Renata Paparelli ${ }^{1}$

Leny Sato ${ }^{2}$

Fábio de Oliveira ${ }^{3}$

\section{A Saúde Mental relacionada ao trabalho e os desafios aos profissionais da saúde}

\author{
Work-related Mental Health and challenges for healthcare \\ personnel
}

\author{
1 Assistente mestre do Departamento \\ de Psicologia Social da Faculdade de \\ Ciências Humanas e Saúde da Pontifícia \\ Universidade Católica de São Paulo, \\ SP, Brasil. \\ 2 Professora titular do Departamento \\ de Psicologia Social e do Trabalho do \\ Instituto de Psicologia da Universidade \\ de São Paulo, SP, Brasil. \\ ${ }^{3}$ Assistente doutor do Departamento \\ de Psicologia Social da Faculdade de \\ Ciências Humanas e Saúde da Pontifícia \\ Universidade Católica de São Paulo, \\ SP, Brasil. \\ Contato: \\ Renata Paparelli \\ Rua Monte Alegre , 984, sala T-52 - \\ Perdizes, São Paulo-SP \\ CEP 05014-901 \\ E-mail: \\ rpaparel@uol.com.br
}

\section{Resumo}

Este artigo de caráter reflexivo discute a Saúde Mental relacionada ao trabalho no contexto atual. Para isso, aponta para a persistência das ideias que negam o nexo entre o trabalho e a saúde mental e critica sua lógica simplificadora e culpabilizante. Prossegue retomando os conceitos fundamentais do campo da saúde do trabalhador e a contribuição da abordagem do processo saúde-doença da Medicina Social Latino-Americana. Ressalta, em seguida, a relevância e a atualidade do conceito de desgaste mental. Conclui com o delineamento dos desafios para os profissionais da saúde para a compreensão da relação entre saúde e trabalho e os novos horizontes abertos pela legislação que estabelece o Nexo Técnico Epidemiológico Previdenciário (NTEP) e o Fator Acidentário de Prevenção (FAP).

Palavras-chave: saúde mental; trabalho; psicologia social; profissionais de saúde.

\begin{abstract}
This reflective essay discusses work-related mental health in the current context, pointing to the persistence of ideas denying the nexus between work and mental health, and criticizing their simplistic and blaming logic. It goes on by resuming the fundamental concepts in the field of Occupational Health and the contributions of the Latin American social medicine health-disease approach. Then it highlights the relevance and contemporaneity of the concept of mental wearing down. It concludes by outlining health professionals' challenges to understand the relationship between health and work, and the new horizons opened by Brazilian Social Security legislation with the introduction of Technical Epidemiological Nexus (NTEP) and Accident Prevention Factor (FAP).
\end{abstract}

Keywords: mental health; work; social psychology; healthcare personnel. 


\section{Introdução}

A relação entre saúde mental e trabalho é um tema muito em voga no Brasil nos últimos anos e constitui um campo de estudos que poderíamos melhor nomear como "Saúde Mental Relacionada ao Trabalho" (SMRT). Essa discussão pode ser apreendida pela variedade de tipos de publicações que apresentam o tema: artigos em periódicos científicos, livros, materiais sindicais, apresentações em congressos, além de ser comumente tema de semanas internas de prevenção de acidentes de trabalho (SIPATs). Atualmente, essa relação também é objeto de normas técnicas e de protocolos para orientar os profissionais de saúde. Além disso, os problemas de adoecimento mental continuam a demandar atendimento em serviços públicos e têm motivado o afastamento do trabalho e a aposentadoria por invalidez de muitos trabalhadores do setor formal de trabalho (JACQUES, 2007; SAMPAIO; MESSIAS, 2002).

O próprio fato de ter havido a iniciativa de editar-se um número especial da Revista Brasileira de Saúde Ocupacional sobre o tema também revela que ele continua a solicitar espaço como objeto de reflexão. Esse fato parece indicar que a divulgação, o debate e a discussão sobre o assunto não têm sido suficientes para mudar o quadro dos problemas de saúde mental relacionados ao trabalho. Mais ainda, constata-se um movimento contraditório: ao mesmo tempo em que se apontam e discutem os contextos de trabalho que explicam a ocorrência desses problemas, testemunha-se não apenas o surgimento de ocupações e profissões que preservam características pouco recomendáveis sob a ótica do campo da SMRT - exemplar é o caso do trabalho em telework, que já motivou a realização de diversos estudos no Brasil, como, por exemplo, o de Ramalho et al. (2008) -, como também se constata que ainda há quem duvide da existência do nexo entre saúde mental e trabalho!

\section{Por que ainda precisamos falar sobre o tema?}

Diante dessa situação, nós, autores deste artigo, fomos levados a interrogar sobre o porquê de ainda haver a necessidade de informar e afirmar que a saúde mental pode ser afetada pelo trabalho, o que gerou as reflexões reunidas no presente artigo, o qual não pretende ser exaustivo na revisão das diferentes posições sobre o tema.

Temos presenciado situações nas quais as pessoas, muitas delas profissionais de saúde, demonstram descrença na existência de tais relações. Por vezes, temos visto fortes reações de oposição à leitura que incorpora os contextos de trabalho como determinantes dos problemas de saúde mental da população trabalhadora.

E quando referimo-nos à população trabalhadora, estamos falando da maioria das pessoas na idade adulta, ou seja, daqueles que vendem sua força de trabalho e também dos que estão em busca de oportunidades para vendê-la. ${ }^{4}$

Não raramente, em nossa atuação como docentes, deparamo-nos com a contrariedade de alguns estudantes, muitos deles da área da saúde, quando apontamos o processo saúde-doença como socialmente influenciado, como já fora, de algum modo, mostrado por Bernardino Ramazzini no século XVIII em seu famoso livro As doenças dos trabalhadores (RAMAZZINI, 2000).

Essa reação dos estudantes parece ser motivada por, pelo menos, duas posições em relação à compreensão da relação saúde-doença e trabalho. A primeira é a de que a causa última para explicar o adoecimento de trabalhadores e trabalhadoras deveria ser buscada sempre no indivíduo: em suas peculiaridades em termos físicos, fisiológicos, psicossociais e em sua história de vida no núcleo familiar anterior à vida de trabalho. A segunda posição é a adoção da naturalização da ideia de que o trabalho produz sofrimento e não pode ser mudado, como se isso fosse um destino, uma determinação inquestionável e intransponível, cujo curso seria impossível de ser modificado.

Ao mesmo tempo em que cresce a constatação, por meio de estudos e dos relatos das vivências de trabalhadores e trabalhadoras, de que o trabalho (tal qual se configura em suas condições e organização) frequentemente produz adoecimentos, desvaloriza-se a força dessa determinação, como se fosse possível reduzi-la às características dos que adoecem, corroborando um processo conhecido como "culpabilização da vítima" (LIMA; OLIVEIRA, 1995; OLIVEIRA, 2007). Desse modo, é comum ouvirmos diferentes versões da mesma pergunta, "mas porque alguns adoecem e outros não?", pergunta que revela o sofisma acima descrito.

É como se os trabalhadores tivessem que ser idênticos uns aos outros e como se o trabalho que realizam fosse homogêneo. Pesquisas que analisam o cotidiano laboral e as diferenças entre o trabalho prescrito e o trabalho real (DANIELLOU; LAVILLE; TEIGER, 1989) apontam a existência de uma série de diferenças entre postos de trabalho que parecem, em um primeiro momento, idênticos. Como exemplo, podemos falar da atividade de caixa de banco cujos ritmos, pressões, cargas afetivas, responsabilidades são muito diferentes, quer se trate da empresa A ou B, quer se trate de agências localizadas em grandes centros urbanos, em bairros com alta densidade populacional ou em bairros pequenos, onde todo mundo se conhece, quer seja realizada no momento de uma fusão entre bancos ou de uma grande crise financeira.

\footnotetext{
${ }^{4}$ De acordo com Ricardo Antunes (1999), a “classe-que-vive-do-trabalho” exclui apenas “os gestores do capital, seus altos funcionários, que detêm papel de controle no processo de trabalho, de valorização e reprodução do capital no interior das empresas e que recebem rendimentos elevados" (p. 104), os que vivem da especulação e dos juros, os pequenos empresários, a pequena burguesia proprietária rural e urbana.
} 
E, quando se fala que a diversidade interpessoal e a variabilidade intrapessoal deveriam ser respeitadas sob pena de o sofrimento, o incômodo e o adoecimento se expressarem, alguns alunos e ouvintes ficam revoltados! Pois lhes parece impossível conceber que é o trabalho (construído socialmente) que deva ser modificado, e não as pessoas.

Esse reducionismo explicativo exemplifica uma reação relativamente generalizada, que também se manifesta quando são discutidos, no dia a dia, fenômenos do mundo do trabalho que demandariam, na verdade, a compreensão das relações indivíduo e sociedade, indivíduo e contexto de vida. Assim, é frequente que, nas interações cotidianas, sejam buscadas explicações apressadas para os acidentes de trabalho ou para o desemprego, explicações calcadas em características pessoais dos trabalhadores. Isso é analisado por Oliveira (2007), no caso dos acidentados, e por Farina e Neves (2007), no caso dos desempregados. ${ }^{5}$

A lógica que acaba por culpabilizar a vítima ou por naturalizar as condições e a organização do trabalho está presente também na noção de ato inseguro como explicação dos acidentes de trabalho. Oliveira (2007) aponta a persistência desse modelo explicativo nos contextos de trabalho. Segundo o autor:

A principal conclusão a se tirar é que a teoria dos dominós de Heinrich [promotora da ideologia do ato inseguro], difundida durante o "milagre econômico" por órgãos oficiais e por outros meios, estrutura o pensamento e as ações relacionados aos acidentes de trabalho na fábrica estudada. As explicações baseadas nos atos inseguros predominam em função da naturalização dos riscos e de mecanismos institucionais que as reafirmam cotidianamente. (p. 26)

Um fenômeno que tem sido negligenciado e que diz respeito diretamente à SMRT é o alcoolismo induzido pelo trabalho. Basta realizar um breve levantamento bibliográfico para verificar que a maioria dos textos que abordam a relação entre alcoolismo e trabalho o faz em nome da necessidade de erradicar comportamentos improdutivos decorrentes do consumo abusivo de álcool. ${ }^{6}$ Nesse contexto, raramente se cogita a participação da organização do trabalho na produção do transtorno, atribuindo-se maior valor a características supostamente predisponentes presentes no indivíduo, traços de personalidade, problemas psicológicos. Assim, mesmo profissionais que atuam em instituições públicas especialmente dedicadas a essa população, muitas vezes não consideram importante sequer saber o tipo de trabalho que aquelas pessoas realizavam antes do adoecimento e tampouco investigar a participação da atividade laboral no processo de cronificação do agravo à saúde.

Tivemos a oportunidade de supervisionar um estágio em uma dessas instituições que consistiu na realização de oficinas de discussão do tema trabalho com alcoolistas. ${ }^{7}$ Um dos participantes da oficina relatou sua história, que revela claramente o nexo entre alcoolismo e trabalho. Podemos sintetizá-la do seguinte modo: ele operava uma máquina que não contava com dispositivos de segurança e que já havia ocasionado vários acidentes, incluindo amputações de partes de membros superiores; com o ritmo intenso de produção, o risco de acidentes aumentava significativamente. Para dar conta do ritmo e do medo gerado pelo risco, o trabalhador passou a recorrer aos efeitos do álcool, saindo do posto de trabalho para consumir a bebida. Com o tempo, ele passou a levar a cachaça em uma garrafa de água mineral e consumi-la durante a execução do trabalho. Esse fato era de conhecimento de todos, tanto que o seu supervisor indicava disfarçadamente que ele fosse beber um "cafezinho" (a cachaça) quando caía o seu ritmo de produção, sabendo que o consumo de álcool viabilizaria a alta velocidade com que ele conseguia produzir. Certa vez, uma colega de trabalho passou com os cabelos soltos perto da máquina e sofreu um escalpo; o trabalhador foi demitido por ter "causado" o acidente que quase custou a vida da colega e por consumir álcool durante a jornada de trabalho! O mais interessante é que, mesmo nesse caso em que o diagnóstico de "alcoolismo crônico relacionado ao trabalho"8 praticamente se constrói sozinho, a psicóloga da instituição pública especializada em tratamento de usuários de álcool e drogas manteve intacto o seu raciocínio culpabilizante: atribuiu ao inconsciente do trabalhador a escolha de uma atividade profissional que o levaria ao consumo de álcool, como se houvesse uma predisposição individual a desenvolver o transtorno. Argumentamos no sentido de explicitar que, no trabalho desse operador de máquinas, não havia nada que pudesse indicar, nem de longe, a facilitação do consumo de álcool, como seria de se esperar da atividade de alguém que trabalhasse servindo bebidas alcoólicas ou fazendo a segurança de casas noturnas. Mesmo assim, a tese da "escolha inconsciente do trabalho" foi mantida. Ela, ainda, perguntando-se por que o trabalhador não havia mudado de emprego ao perceber que aquele o estava prejudicando, concluiu pela predisposição endógena ao consumo.

Vários outros exemplos poderiam ser apresentados. Diante dessa recorrente reação, pensamos que seria importante tratar do modo como compreendemos fenômenos que envolvem a contextualização das pessoas na vida material e social, compreensão que é essencial no campo

\footnotetext{
${ }^{5}$ Ver também Neves et al. (1998).

${ }^{6}$ Uma das exceções que não afirmam essa lógica é o artigo de Halpern, Ferreira e Silva Filho (2008).

${ }^{7}$ Estagiárias envolvidas: Flávia Thomé Alvarez e Natália Degaki.

${ }^{8}$ Para maiores informações, ver Dias et al. (2001).
} 
da SMRT, área que implica o diálogo constante com outras disciplinas do conhecimento. ${ }^{9}$ Além disso, é necessária a articulação de vários territórios para a compreensão da SMRT (SELIGMANN-SILVA, 1994), que incluem:

- patamar internacional: é preciso considerar a divisão internacional da riqueza, do poder e do trabalho (como exemplo, podemos citar a exportação, dos países ricos para os pobres, de processos e substâncias químicas que oferecem riscos à saúde e que foram recusados pelos trabalhadores dos países de origem);

- contextos nacionais: determinações estruturais, conjunturais, políticas econômicas e de desenvolvimento social, legislação trabalhista e garantia de direitos aos trabalhadores, existência de proteção ao emprego e à saúde, promoção de qualificação social etc.;

- condições gerais de vida: moradia, saneamento básico, alimentação, transporte são fatores que podem elevar o desgaste dos trabalhadores;

- empresas: relações de trabalho, políticas de recursos humanos, tipos de gestão e possibilidades de controle dos trabalhadores;

- espaço microssocial do local de trabalho: aspectos coletivos, dinâmicas intersubjetivas;

- individualidade: espaço no qual o indivíduo singular, em sua trajetória pessoal, irá se "confrontar ativamente com as forças emanadas dos demais territórios examinados e penetrar na malha de suas interações” (p. 71).

Desse modo, os estudos no campo da SMRT representam um desafio aos pesquisadores:

Um desafio para os pesquisadores do novo é, portanto, o de integrar, de forma compreensiva, as contribuições dos autores que têm se preocupado em analisar as instâncias "macro" às daqueles que têm estudado fenômenos microssociais, nas equipes e nos/dos locais de trabalho e, ainda, às dos que detectam a complexidade da dinâmica intrapsíquica decorrente da vida e da experiência laboral. (SELIGMANN-SILVA, 1994, p. 71)

\section{Colaborando para enfrentar a lógica simplificadora e culpabilizante em saúde}

A crítica realizada pelo campo teórico-prático da Saúde e Trabalho e pela abordagem da Medicina Social Latino-Americana às concepções hegemônicas de saúde e das determinações do processo saúde-doença permitem-nos questionar a simplificação ideológica que atribui apenas aos indivíduos e às suas características pessoais as causas de seus problemas de saúde, em geral, e os relacionados ao trabalho, em particular. Essa crítica também possibilitou a construção dos pilares de uma outra concepção acerca da gênese e da constituição do sofrimento psíquico humano, a teoria do Desgaste Mental (SELIGMANN-SILVA, 1986). Vejamos agora os elementos básicos da crítica para posteriormente conhecermos a teoria do Desgaste Mental.

\section{a) SMRT e a Saúde do Trabalhador, alguns conceitos fundamentais ${ }^{10}$}

O campo da Saúde do Trabalhador emerge como um discurso contra-hegemônico - campo de práticas teóricas (geração de conhecimentos) e práticas político-ideológicas (visando à superação das relações de poder) - no contexto do ressurgimento do movimento sindical no Brasil, no final da década de 1970. Constituído pelos vetores da produção acadêmica, da programação em saúde na rede pública e pelo movimento dos trabalhadores, busca compreender a determinação do processo saúde-doença, privilegiando o trabalho (SATO; BERNARDO, 2005; LACAZ, 2007). Nesse modo de entender a relação saúde-doença e trabalho, o trabalhador comparece como sujeito, ao lado de saberes acadêmicos e de profissionais da saúde, na luta pela transformação dos processos de trabalho, "visando a resgatar o real ethos do trabalho: libertário e emancipador" (LACAZ, 2007, p. 760). Esse lugar ocupado pelos trabalhadores nas práticas do campo da Saúde do Trabalhador configura-se como premissa metodológica, sendo o trabalho do psicólogo Ivar Oddone (ODDONE et al., 1986) paradigmático nesse sentido, conforme vemos em Minayo-Gomez e Thedim-Costa (1997):

(...) uma premissa metodológica é a interlocução com os próprios trabalhadores, depositários de um saber emanado da experiência e sujeitos essenciais quando se visa a uma ação transformadora. O reconhecimento desse saber/poder foi o sustentáculo do "Modelo Operário Italiano" (ODDONE et al., 1986), que emergiu no bojo do dinamismo dos movimentos sociais, em finais dos anos 70, tendo como foco particular a mudança e o controle das condições de trabalho nas unidades produtivas. A não-delegação, expressa pela recusa em transferir para técnicos ou representantes sindicais a tarefa de sistematizar o conhecimento obtido pelos grupos submetidos às mesmas condições de trabalho - grupos homogêneos - e a validação consensual, resultante da discussão coletiva das avaliações que pautariam os processos reivindicatórios, constituíram-se nos pressupostos básicos desse modelo. (p. 29)

Os elementos básicos da perspectiva da Saúde do Trabalhador são os seguintes (SATO, 1995):

\footnotetext{
${ }^{9}$ Segundo Seligmann-Silva (1994), são exemplos dessas disciplinas: Medicina do Trabalho, Psicologia do Trabalho, Psicopatologia do Trabalho, Toxicologia, Ergonomia, Psicanálise, Fisiologia, Neurologia, Psiquiatria, Medicina Psicossomática, Economia Política, Estudos sobre Organização do Trabalho, Ciências Sociais, Filosofia.

${ }^{10}$ Esse tópico, bem como os dois seguintes, caracterizam-se como uma reformulação de texto contido na tese de doutorado de Paparelli (2009).
} 
- o trabalho não pode ser reduzido ao ambiente de trabalho. As regras que definem a convivência entre patrões e empregados, as hierarquias, o ritmo, as formas de avaliação, a possibilidade de controle do trabalho, ou seja, a divisão do poder (divisão entre quem pensa e quem executa, quem manda e quem só deve obedecer) define as condições de trabalho. A categoria teórica ampliada que inclui esses aspectos é a "organização do trabalho";

- a consideração da presença de sofrimento ou desgaste mental relacionado ao trabalho como indícios de sua penosidade, ainda que não se configurem como doenças propriamente ditas;

- o questionamento quanto à definição de saúde preconizada pela Organização Mundial de Saúde (OMS) como um "estado de bem-estar biopsicossocial".

Quanto a esse último aspecto, Canguilhem (1995) traz elementos para o questionamento do conceito de saúde tal como definido pela OMS. Segundo Neves, Seligmann-Silva e Athayde (2004), Canguilhem:

[...] aponta a saúde e a doença como dimensões constitutivas do processo dinâmico que é a vida, estando cada uma dessas dimensões contida na outra [...] afirma que saúde diz respeito à capacidade de o ser vivo estabelecer normas, de tolerar e enfrentar as infidelidades e as agressões do meio (na medida em que o normal se constitui das variabilidades e flutuações desse meio), o que é mais do que adaptar-se. Ser saudável significa, então, ser capaz de detectar, interpretar e reagir - enfim, é a capacidade de cair enfermo (ficar doente) e poder recuperar-se. [...] A normalidade e a anormalidade fazem parte do campo da saúde, o que não implica a doença. Dessa forma, segundo o autor, os conceitos de saúde e enfermidade devem ser pensados a partir da correlação que se estabelece entre determinações sociais e limites ou capacidades vitais. A capacidade de tolerância para enfrentar as dificuldades está, portanto, diretamente associada a valores biológicos e sociais. (p. 44-45)

Dejours (1986), seguindo o mesmo raciocínio, critica o conceito a partir da dificuldade de definir o que seria um perfeito "estado de bem-estar biopsicossocial”, da impossibilidade de alcançá-lo e da natureza mutante e conflituosa da vida humana. Se o que caracteriza o humano é justamente o movimento, o transformar-se, o diferenciar-se de si mesmo durante a vida, como pode a saúde definir-se pela noção de estabilidade? Se o que leva ao movimento são os conflitos vividos e seus afetos correlatos, como pode a saúde caracterizar-se pela noção de harmonioso bem-estar?

Desse modo, para Dejours (1986):

[...] a saúde para cada homem, mulher ou criança é ter meios de traçar um caminho pessoal e original, em direção ao bem-estar físico, psíquico e social. A saúde, portanto, é possuir esses meios. [...] O que significa possuir esses meios e o que é esse bem-estar? Creio que para o bem-estar físico é preciso a liberdade de regular as variações que aparecem no estado do organismo; temos o direito de ter um corpo que tem von- tade de dormir, temos o direito de ter um corpo que está cansado (o que não é forçosamente anormal) e que tem vontade de repousar. A saúde é a liberdade de dar a esse corpo a possibilidade de repousar, é a liberdade de lhe dar de comer quando ele tem fome, de fazê-lo dormir quando ele tem sono, de fornecer-lhe açúcar quando baixa a glicemia. É, portanto, a liberdade de adaptação. Não é anormal estar cansado, estar com sono. Não é, talvez, anormal ter uma gripe, e aí vê-se que isso vai longe. Pode ser até que seja normal ter algumas doenças. O que não é normal é não poder cuidar dessa doença, não poder ir para a cama, deixar-se levar pela doença, deixar que as coisas sejam feitas por outro durante algum tempo, parar de trabalhar durante a gripe e depois voltar. Bem-estar psíquico, em nosso entender, é, simplesmente, a liberdade que é deixada ao desejo de cada um na organização de sua vida. E por bem-estar social, cremos que aí também se deve entender a liberdade, é a liberdade de se agir individual e coletivamente sobre a organização do trabalho, ou seja, sobre o conteúdo do trabalho, a divisão das tarefas, a divisão dos homens e as relações que mantêm entre si. (p. 11)

Sato (1995) aprofunda a discussão sobre a saúdedoença e sua relação com a organização do trabalho. Essa categoria conceitual chave na Saúde do Trabalhador tem como núcleo as questões do poder e do controle do trabalhador sobre o próprio trabalho. Em pesquisa sobre a penosidade do trabalho de condutores de ônibus urbanos, a autora verifica que, para que se possa afirmar a presença de controle efetivo por parte dos trabalhadores, ou seja, para que se possa afirmar que uma determinada atividade não seja penosa, geradora de desgaste mental, três requisitos devem estar presentes simultaneamente:

- o poder, que diz respeito à possibilidade de o trabalhador interferir no planejamento do trabalho de modo a modificar os contextos que geram incômodo, sofrimento e esforço em demasia;

- a familiaridade, que se refere à experiência do trabalhador no desempenho da tarefa;

- o limite subjetivo, que deve nortear o quando, o quanto e o como o trabalhador suporta as demandas do trabalho.

Em síntese, a perspectiva da Saúde do Trabalhador parte da concepção de que a saúde configura-se como um processo e não um estado, sendo que o mais importante nesse processo é o ser humano ali comparecer como sujeito, como alguém com condições e instrumentos para interferir naquilo que lhe causa sofrimento. Essa perspectiva considera os indivíduos em sua diversidade (são diferentes uns dos outros) e variabilidade (são variáveis com relação a si mesmos conforme os diversos momentos pelos quais passam no decorrer de sua existência). As possibilidades de ação no mundo, de intervenção na realidade remetem aos contextos de vida, especialmente ao trabalho e, no interior dessa esfera, à organização do trabalho, divisão das pessoas e das tarefas, divisão do poder de intervir nos contextos de trabalho de modo a torná-los articulados ao processo de saúde. 


\section{b) A contribuição da abordagem do processo saúde- -doença da Medicina Social Latino-Americana}

A Medicina Social Latino-Americana representa um marco dentre as abordagens da medicina construídas no início dos anos 1970, constituindo um modelo de investigação do processo saúde-doença que afirma sua historicidade e busca compreender a multiplicidade de suas determinações. O processo de trabalho emerge como uma das mais importantes dentre essas determinações.

Laurell e Noriega (1989), no livro Processo de produção e saúde: trabalho e desgaste operário, apresentam essa abordagem, que, tomando por base a teoria marxista, coloca no centro de análise o trabalho compreendido no interior das relações de produção capitalistas. Embora a questão principal de sua obra não seja a saúde mental relacionada ao trabalho, mas sim a compreensão dos padrões de desgaste vividos pelas distintas categorias de trabalhadores, sua proposta traz relevantes contribuições ao estudo dos agravos à saúde mental relacionados ao trabalho, especialmente no que se refere à sua inclusão no bojo dos conflitos entre capital e trabalho.

O método utilizado para dimensionar o desgaste da força de trabalho consiste na decomposição e posterior recomposição do processo de trabalho, definido como "materialização do processo de valorização e divisão do trabalho, somente decifrável a partir dele" (p. 105). Deve-se decompor o processo de trabalho em seus elementos constituintes (ou seja, o objeto de trabalho, os instrumentos de trabalho e o próprio trabalho), em seus aspectos técnicos (características físicas, químicas e mecânicas) e sociais (a organização e a divisão do trabalho, bem como seu desenvolvimento histórico). Deve-se reconstituir o processo de trabalho, propiciando "[...] a integração cada vez mais complexa dos elementos, no marco de uma dinâmica global que imprime uma nova qualidade ao conjunto" (p. 109). Ou seja, o processo de trabalho deve ser reconstituído como "processo global" na busca da "lógica que ordena as partes e lhes dá integridade". Desse modo, a reconstituição não pode ser confundida com uma "síntese meramente somatória" das partes decompostas, com a busca de relações de causa e efeito mecanicistas (mono ou multicausais) ou de fatores de risco, sob pena de se perder nesse procedimento a compreensão das formas através das quais interagem os elementos entre si e com os trabalhadores. Daí é que se pode falar em relações de determinação dos agravos à saúde pelo processo de trabalho, em contraposição às noções de "determinismo" ou "causalidade". ${ }^{11}$

O desgaste operário assume diversas formas de acordo com o processo de trabalho. Laurell e Noriega (1989) fazem uma revisão dos reflexos de diferentes processos de produção sobre a saúde dos trabalhadores e verificam que, no interior das transformações que levam do trabalho artesanal ao taylorismo, passando pelo fordismo e a automação, a dominação e o controle do capital sobre o trabalho intensificam-se e diminuem as possibilidades de o trabalhador ter controle sobre seu próprio trabalho. Essas formas de organização do trabalho, que representam a separação entre concepção e execução e a apropriação capitalista do saber-fazer dos trabalhadores, procuram converter o sujeito-trabalhador em objeto, em fator objetivo do processo de produção, em coisa sem subjetividade. Essas características do processo de trabalho são traduzidas em cargas de trabalho. ${ }^{12}$

Os mesmos autores questionam a noção de risco ocupacional (que estabelece relações de causalidade simples entre os agentes/fatores de risco e as patologias do trabalho), propondo a categoria "carga de trabalho”, que diz respeito às exigências da organização do trabalho e da atividade do trabalhador. Há as "cargas com materialidade externa” (físicas, químicas, biológicas etc.) e as "com materialidade interna" (ritmo, controle, tensão psíquica etc.). Essas cargas interagem dinamicamente entre si e com o corpo do trabalhador, do que decorre o possível desgaste dos trabalhadores, desgaste esse que resulta dos processos adaptativos que ocorrem em cada trabalhador e é definido como perda da capacidade biopsíquica efetiva ou potencial, não se configurando necessariamente como doença instalada. O padrão de desgaste de um determinado grupo de trabalhadores pode ser identificado na relação entre processo de valorização, processo de trabalho, cargas de trabalho e processo de desgaste.

As cargas psíquicas são aquelas que deixam mais clara a submissão de todas as cargas à lógica da produção capitalista, só podendo ser entendidas no interior dela:

No caso das cargas psíquicas, ressalta com particular clareza que são socialmente produzidas e que não podem ser compreendidas como "riscos" isolados, ou abstratos, à margem das condições que as geram. Todavia, isso é também certo para o restante das cargas, incluindo aquelas que têm materialidade externa à corporeidade humana. Ou seja, se bem o ruído seja ruído, e como tal origina transformações no processo biopsíquico, não é irrelevante perguntar por que se produz e porque

\footnotetext{
${ }^{11}$ Esse método remete ao empregado por Marx, em 0 Capital, na análise do modo de produção capitalista, entendido como uma totalidade complexa, síntese de múltiplas determinações categoriais (sendo as categorias expressões de relações sociais complexas, propriedades essenciais do concreto). As categorias analisadas por Marx para que a totalidade concreta "capitalismo" seja compreendida são a mercadoria, o dinheiro, o capital e o salário.

${ }^{12}$ Laurell e Noriega (1989) referem-se ao taylorismo-fordismo e não ao toyotismo. Bernardo (2009) revela que, apesar das afirmações de que a empresa toyotista superou os problemas do modelo taylorista-fordista - devolvendo o controle do trabalho ao trabalhador a partir de sua inserção em “equipes de trabalho", de seu desempenho estar associado à “participação”, à "autonomia” e à "competência” -, não é isso o que se verifica quando os próprios trabalhadores se põem a falar sobre seu trabalho. Na vivência dos trabalhadores que ela entrevistou, aparecem com maior frequência o sofrimento e a dor intimamente relacionados ao excesso de responsabilidades, à humilhação cotidiana e à imposição de ritmo de trabalho, responsáveis pelo adoecimento dos trabalhadores.
} 
se mantém num determinado nível. Ao tentar responder a essas perguntas com relação a qualquer carga, aparecem invariavelmente dois fatos. Um é que surge como expressão particular da forma específica de produzir (das características da base técnica e dos objetos empregados, mas também da organização e divisão do trabalho). Outro é que a intensidade, e ainda a presença ou não das cargas não é alheia às relações de força entre capital e trabalho num centro de trabalho concreto e na sociedade. (LAURELL; NORIEGA, 1989, p. 113)

Ainda sobre essas cargas psíquicas presentes nos processos de trabalho, pode-se dizer que, segundo Laurell e Noriega (1989), dividem-se em dois tipos: a sobrecarga psíquica, decorrente de situações de tensão prolongada (exemplos: atenção permanente, supervisão com pressão, consciência da periculosidade do trabalho, altos ritmos de trabalho); a subcarga psíquica, relacionada a situações em que o trabalhador é impossibilitado de fazer uso de suas capacidades psíquicas no trabalho (exemplos: perda do controle sobre o trabalho ao estar o trabalhador subordinado ao movimento da máquina; desqualificação do trabalho, resultado da separação entre concepção e execução; a parcelização do trabalho, que redunda em monotonia e repetitividade).

Lacaz (2007) sintetiza as principais características da Medicina Social Latino-Americana:

A Medicina Social Latino-Americana apreende-o [o trabalho] através do processo de trabalho, categoria explicativa que se inscreve nas relações sociais de produção estabelecidas entre capital e trabalho. E, conforme a acepção marxista, aqui o trabalho é, ontologicamente, a ação do homem sobre a natureza para modificá-la e transformá-la e a si mesmo, não sendo, portanto, externa ao homem. Tal ação vai ocorrer sobre o objeto de trabalho, mediante os instrumentos de trabalho, configurando o próprio trabalho e suas diferentes formas de organização, divisão, valorização, características de cada formação social e modo de produção, o que imprime um caráter histórico ao estudo das relações trabalho-saúde e, conseqüentemente, do adoecimento pelo trabalho. Importa, então, desvendar a nocividade do processo de trabalho sob o capitalismo e suas implicações: alienação; sobrecarga e/ou subcarga; pela interação dinâmica de "cargas" sobre os corpos que trabalham, conformando um nexo biopsíquico que expressa o desgaste impeditivo da fluição das potencialidades e da criatividade. (p. 759-760, grifos do autor)

\section{c) $\mathrm{O}$ desgaste mental: afirmando a compreensão mar- xista da SMRT}

Nessa perspectiva, os elementos presentes na organização e no ambiente do trabalho (divisão do trabalho, conteúdo das tarefas, ritmo de trabalho, relações de poder, condições ambientais, formas de avaliação e controle, hierarquias etc.) são entendidos como "fontes laborais de tensão”, que provocam o desgaste que se manifesta por diferentes configurações. Esse conceito, por sua abrangência, propicia o avanço dos estudos do campo SMRT e permite:

[...] instrumentar o necessário estudo da gênese da tensão que vai se tornar em sofrimento e sem que este sofrimento deixe de ser examinado em suas diferentes configurações: fadiga, depressão, distúrbios psicossomáticos, síndromes neuróticas, reações psicóticas, alcoolismo etc. (SELIGMANN-SILVA, 1986, p. 66)

Muitos processos de desgaste orgânico determinados pelo trabalho são bem conhecidos, assim como a existência de danos decorrentes de processos de trabalho que atingem o substrato orgânico do psiquismo, como no caso de determinados acidentes de trabalho e de intoxicações que exercem efeitos destrutivos ou prejudiciais aos processos bioquímicos do sistema nervoso, ocasionando déficits intelectuais ou transtornos de ordem psicoafetiva (exposição a chumbo, mercúrio ou a outros metais pesados). Há também agentes biológicos e físicos capazes de agredir o sistema nervoso.

Mas o que se pode dizer quando não há acometimento desse substrato orgânico? Seligmann-Silva (1994) coloca-se a seguinte questão:

Será possível reconhecer um desgaste das capacidades mentais-(cognitivas e psico-afetivas) determinado pelo trabalho, de forma independente da ocorrência de "desgaste" ou da destruição de estruturas do sistema nervoso central? (p. 78)

Para respondê-la, a autora emprega a noção de "perda" ou "expropriação" subjetivas vividas pelos trabalhadores em processos de trabalho nos quais eles devem comparecer como coisas sem subjetividade, ou seja, em contextos de intensa sujeição. Em suas palavras:

Temos, assim, uma outra vertente de análise, quando consideramos a forma pela qual a situação de trabalho dominado/explorado atua sobre a subjetividade, que modula relações e usos pessoais do tempo, do espaço, dos próprios gestos e pensamentos. Este seria o "trabalhador por inteiro", que estaria exposto a ser expropriado de componentes importantes de sua subjetividade, no interior daquelas situações onde a sujeição é intensa [...]. (p. 79, grifo da autora)

Fortalecendo o argumento de que os agravos mentais decorrentes do trabalho podem ser explicados por meio da noção de desgaste mental, a autora, partindo do referencial teórico do materialismo histórico, resgata a definição de desgaste proposta por Laurell e Noriega (1989), que implica "perda de capacidade potencial e/ou efetiva, corporal e psíquica" e a afirmação desses mesmos autores, bem como de Doray (1981), sobre a utilização deformada e deformante das potencialidades psíquicas e do próprio corpo do trabalhador no trabalho alienado. Se há perda e deformação, ou seja, se há transformações negativas de um estado anterior mais satisfatório, pode-se entender o desgaste mental como processo constituído de "experiências que se constroem diacronicamente, ao longo das experiências de vida laboral e extralaboral dos indivíduos" (SELIGMANN-SILVA, 1994, p. 80).

Seligmann-Silva (1986) também deixa claro o seu entendimento sobre a participação do trabalho na produção de transtornos mentais, considerando possíveis tanto o papel desencadeador, quanto o de produtor dos agravos. Em pesquisa que realizou com trabalhadores do setor siderúrgico nos anos 1980, verificou o seguinte: 
A discussão referente ao tipo de ação - predisponente ou desencadeante - assumida pelas condições ambientais e organizacionais do trabalho, tem permanecido acesa, como já vimos. Para os trabalhadores do setor siderúrgico que haviam estado por longos anos expostos a condições de trabalho extremamente penosas, a análise de seus históricos de vida, trabalho e saúde conduziu-nos, muitas vezes, a perceber que o acúmulo dessas experiências se constitui em verdade um processo preparatório e predisponente à instalação das manifestações psicopatológicas. E que este processo gradualmente foi minando a vitalidade, as resistências da personalidade e, muitas vezes, também a esperança. Foi assim que concluímos, para os casos estudados, que pôde ser verificado que as condições laborais tanto tiveram ações predisponentes, como exerceram efeitos desencadeantes de quadros psicopatológicos diversos. E ainda, que a agudização das exigências laborais, em circunstâncias muitas vezes decorrentes da crise econômica, para pessoas já anteriormente em estado de fadiga crônica, representou clara ação desencadeante de crises mentais, que, em vários dos casos estudados, conduziu à hospitalização psiquiátrica. (p. 86, grifos da autora)

Entendemos que a definição do "desgaste mental" como "a presença de perda ou de transformações negativas na subjetividade, nas capacidades e faculdades humanas" traz uma aparente simplicidade, que potencializa a interlocução com os diversos profissionais envolvidos com SMRT. Os significados do verbete "desgaste" (HOUAISS, 2001) - "ação ou efeito de desgastar(-se); desgasto", "alteração ou redução da forma, por fricção ou atrito; corrosão", "consumição pelo tempo, pelo esforço; destruição, envelhecimento, ruína" ou ainda "redução da capacidade, do poder; abatimento, enfraquecimento" - convidam a pensá-lo como um processo no qual estão presentes pelo menos dois elementos, o que é desgastado e o que produz o desgaste, o que remete a interrogações sobre os elementos desse processo e as determinações do sofrimento mental.

Ao mesmo tempo em que é uma noção aparentemente simples, o conceito de desgaste guarda a complexidade na compreensão dos agravos à saúde mental relacionados ao trabalho, uma vez que permite superar os limites e os contornos dos diferentes objetos estudados a partir de diferentes leituras teórico-metodológicas. Além disso, é coerente com a perspectiva da Saúde do Trabalhador, trazendo uma visão ampliada do processo saúde-doença e a categoria "organização do trabalho" como norteadora da análise.

\section{Os desafios dos profissionais de saúde}

Entendemos que os desafios a serem enfrentados pelos profissionais de saúde são grandes e urgentes. Há que se compreender melhor, no dia a dia de trabalho das equipes dos Cerests (Centros de Referência em Saúde do Trabalhador), do PSF (Programa de Saúde da
Família, Atenção Básica à Saúde), das UBSs (Unidades Básicas de Saúde), dos CAPSs (Centros de Atenção Psicossociais), dos consultórios particulares etc., a imbricação entre as questões de saúde e a vida dos usuários, vida essa que inclui sua trajetória pessoal, as questões familiares, educacionais, subjetivas e também aquelas relacionadas ao trabalho ou à ausência dele. Além de compreender, é preciso incluir essas dimensões na assistência e no trabalho preventivo, guardadas as devidas especificidades de programas e instituições.

É necessário enfrentar as falsas perguntas que surgem, muitas vezes, de modo automático, quando os profissionais se veem diante de alguém em situação de adoecimento, perguntas tais como: por que ele adoeceu e não outras pessoas? Por que ele não procurou outro trabalho? O que há de singular que explique o adoecimento? Ampliar essas questões é se perguntar: será que não há outras pessoas no mesmo trabalho ou categoria profissional que apresentam esse mesmo quadro? Seria possível desconsiderar os anos de dedicação e empenho a uma determinada atividade e procurar outro trabalho, ainda mais em tempos de desemprego? O que esse quadro me diz desse sujeito e de seu contexto maior de vida e trabalho? Como se produziu esse agravo no decorrer e no interior de sua vida? Enfim, é necessário que se possa partir do questionamento da ideia de que o indivíduo possa construir a si mesmo sozinho e que, desse modo solitário, também possa enfrentar e superar as dificuldades vividas.

O enfrentamento desses desafios é especialmente importante no contexto atual, em que passa a vigorar o Nexo Técnico Epidemiológico Previdenciário (BRASIL, 2006). Trata-se de lei que permite à previdência social conceder benefício acidentário ao trabalhador incapacitado para o trabalho que seja acometido por doença cujo risco de adquiri-la seja maior no ramo econômico ao qual pertence a empresa em que trabalha, ou seja, com base em critério epidemiológico. Também inverte o ônus da prova, instituindo que cabe ao empregador provar que os trabalhadores acometidos por agravos à saúde com alta prevalência no ramo econômico considerado não adoeceram por causa do trabalho, diferentemente da lógica anterior, em que o trabalhador é quem tinha que provar que seu problema estava relacionado ao trabalho que realizava. Além disso, o Fator Acidentário de Prevenção (FAP) permite taxar mais as empresas que mais acidentaram e adoeceram num determinado período de tempo, tendo como referência a alíquota do ramo econômico a que pertence.

Essa nova legislação, que representa uma conquista dos trabalhadores e estimula a prevenção, coloca em destaque o tema da construção do nexo entre SMRT e os desafios presentes nessa empreitada. ${ }^{13}$

\footnotetext{
${ }^{13}$ Dentre os pesquisadores brasileiros empenhados nessa tarefa, destaca-se Lima $(2002,2003,2005)$.
} 


\section{Contribuições de autoria}

Os três autores contribuíram igualmente para a realização da revisão teórica apresentada e para a elaboração do manuscrito cuja versão final recebeu aprovação de todos.

\section{Referências}

ANTUNES, R. Os sentidos do trabalho: ensaio sobre a afirmação e a negação do trabalho. São Paulo: Boitempo, 1999.

BERNARDO, M. H. Trabalho duro, discurso flexível: uma análise das contradições do toyotismo a partir da vivência dos trabalhadores. São Paulo: Expressão Popular, 2009.

BRASIL. Lei Federal no 11.430, de 26 de dezembro de 2006. Altera as Leis $\mathrm{n}$ os 8.213 , de 24 de julho de 1991, e 9.796, de 5 de maio de 1999, aumenta o valor dos benefícios da previdência social; e revoga a Medida Provisória no 316, de 11 de agosto de 2006; disposotivos das Leis n $\underline{\text { os }} 8.213$, de 24 de julho de 1991, 8.444, de 20 de julho de 1992, e da Medida Provisória no 2.187-13, de 24 de agosto de 2001; e a Lei no 10.699 , de 9 de julho de 2003. Disponível em: <http://www.planalto.gov.br/ccivil/_ato20042006/2006/lei/11430.htm >. Acesso em: 08 abr. 2011.

CANGUILHEM, G. O normal e o patológico. 4. ed. Rio de Janeiro: Forense Universitária, 1995.

DANIELLOU, F.; LAVILLE, A.; TEIGER, C. Ficção e realidade do trabalho operário. Revista Brasileira de Saúde Ocupacional, São Paulo, v. 17, n. 68, p. 7-13, 1989.

DEJOURS, C. Por um novo conceito de saúde. Revista Brasileira de Saúde Ocupacional, São Paulo, v. 14, n. 54, p. 7-11, 1986.

DIAS, E. C. et al. (Org.). Doenças relacionadas ao trabalho: manual de procedimentos para os serviços de saúde. Ministério da Saúde: Brasília, DF: 2001.

DORAY, B. Le taylorisme, une folie rationelle? Paris: Bordas, 1981.

FARINA, A. S.; NEVES, T. F. S. Formas de lidar com o desemprego: possibilidades e limites de um projeto de atuação em psicologia social do trabalho. Cadernos de Psicologia Social do Trabalho, v. 10, n. 1, p. 21-36, 2007.

HALPERN, E. E.; FERREIRA, S. M. B.; SILVA FILHO, J. F. Os efeitos das situações de trabalho na construção do alcoolismo de pacientes militares da marinha do Brasil. Cadernos de Psicologia Social do Trabalho, v. 11, n. 2, p. 273-286, 2008.

HOUAISS, A. Dicionário eletrônico Houaiss da língua portuguesa. São Paulo: Objetiva, 2001.

JACQUES, M. G. O nexo causal em saúde/doença mental no trabalho: uma demanda para a psicologia, Psicologia e Sociedade, Florianópolis, v. 19, n. 1, p. 112-119, 2007. Edição Especial.
LACAZ, F. A. C. O campo da saúde do trabalhador: resgatando conhecimentos e práticas sobre as relações trabalho-saúde. Cadernos de Saúde Pública, Rio de Janeiro, v. 23, n. 4, p. 757-766, 2007.

LAURELL, A. C.; NORIEGA, M. Processo de produção e saúde: trabalho e desgaste operário. São Paulo: Hucitec, 1989.

LIMA, A. B., OLIVEIRA, F. Repercussões psicossociais da LER: grupos de qualidade de vida e ideologia da culpabilização. In: CODO, W.; ALMEIDA, M. C. C. G.. (Org.). Lesões por esforços repetitivos diagnóstico, tratamento e prevenção: uma abordagem multidisciplinar. Petrópolis: Vozes, 1995. p. 136-159.

LIMA, M. E. A. Esboço de uma crítica à especulação no campo da saúde mental e trabalho In: JACQUES, M. G.; CODO, W. (Orgs.). Saúde mental e trabalho: leituras. Petrópolis: Vozes, 2002. p. 50-81.

. A polêmica em torno do nexo causal entre distúrbio mental e trabalho. Psicologia em Revista, Belo Horizonte, v. 10, n. 14, p. 82-91, 2003.

. Transtornos mentais e trabalho: o problema do nexo causal. Revista de Administração da FEAD-Minas, Belo Horizonte, v. 2, n. 1, p. 73-80, 2005.

MINAYO-GOMEZ, C.; THEDIM-COSTA, S. M. F. A construção do campo da saúde do trabalhador: percurso e dilemas. Cadernos de Saúde Pública, Rio de Janeiro, v. 13, p. 21-32, 1997. Suplemento.

NEVES, M. Y. R.; SELIGMANN-SILVA, E.; ATHAYDE, M. Saúde mental e trabalho: um campo em construção. In: ARAÚJO, A. M. F. et al. (Orgs). Cenários do trabalho: subjetividade, movimento e enigma. Rio de Janeiro: DP\&A, 2004. p. 19-49.

NEVES, T. F. S. et al. Desemprego e ideologia: as explicações das causas do desemprego utilizadas por trabalhadores metalúrgicos. Cadernos de Psicologia Social do Trabalho, São Paulo, v. 1, n. 1, p. 1-13, 1998.

ODDONE, I. et al. Ambiente de trabalho: a luta dos trabalhadores pela saúde. São Paulo: Hucitec, 1986.

OLIVEIRA, O. A persistência da noção de ato inseguro e a construção da culpa: os discursos sobre os acidentes de trabalho em uma indústria metalúrgica. Revista Brasileira de Saúde Ocupacional, São Paulo, v. 32, n. 115, p. 19-27, 2007.

PAPARELLI, R. Desgaste mental do professor da rede pública de ensino: trabalho sem sentido sob a política de regularização de fluxo escolar. 2009. 193f. Tese (Doutorado)-Instituto de Psicologia, Universidade de São Paulo, São Paulo, 2008. 
RAMALHO, C. C. et al. Viver na baia: dimensões psicossociais da saúde e do controle no trabalho de teleatendimento. Cadernos de Psicologia Social do Trabalho, São Paulo, v. 11, n. 1, p. 19-39, 2008.

RAMAZZINI, B. As doenças dos trabalhadores. São Paulo: Fundacentro, 2000.

SAMPAIO, J. J. C.; MESSIAS, E. L. M. A epidemiologia em saúde mental e trabalho. In: JACQUES, M. G.;

CODO, W. G. (Org.). Saúde mental \& trabalho: leituras. Petrópolis: Vozes, 2002. p. 143-171.

SATO, L. A representação social do trabalho penoso. In: SPINK, M. J. P. (Org.). O conhecimento no cotidiano: as representações sociais na perspectiva da psicologia social. São Paulo: Brasiliense, 1995. p. 188-211.

SATO, L.; BERNARDO, M. H. Saúde mental e trabalho: os problemas que persistem. Ciência e Saúde Coletiva, Rio de Janeiro, v. 10, n. 4, p. 869-878, 2005.

SELIGMANN-SILVA, E. Crise econômica, trabalho e saúde mental. In: ANGERAMI, V. A. et al. (Orgs.). Crise, trabalho e saúde mental no Brasil. São Paulo: Traço, 1986. p. 54-132.

. Desgaste mental no trabalho dominado. Rio de Janeiro: Cortez, 1994. 